\title{
Cost-efficient co-creation of knowledge intensive business services
}

Seppo Kuula1 · Harri Haapasalo1 · Arto Tolonen1

Department of Industrial Engineering and Management, University of Oulu, P.O. Box 4610, 90014 Oulu, Finland

Kuula, S., Haapasalo, H. \& Tolonen, A. Serv Bus (2018) 12: 779.

https://doi.org/10.1007/s11628-018-0380-y

This is a post-peer-review, pre-copyedit version of an article published in Service Business. The final authenticated version is available online at:

https://doi.org/10.1007/s11628-018-0380-y. 


\section{Introduction}

Digitalization and the expanding service businesses in all developed economies are driving the need for more service-oriented marketing and business logic, simultaneously increasing the importance of knowledge-based occupations (Starbuck 1992; Castells 2010). A baseline for service marketing is that customers consume a service (regardless of whether they are buying goods or services), whereas marketing concerns relationships, networks, and interactions (Grönroos 1979; Gummesson 1999). Service science defines service systems as value creational configurations of people, technology, value propositions, and shared information (which does not result in ownership) (Maglio and Spohrer 2008). Due to the intangibility, uniqueness, and immediate consumption of services, the efficiency of service provision is challenging to determine.

Service-dominant logic (SDL) implies that value is achieved from the integration of skills, knowledge, and processes and that it is co-created with the consumer rather than embedded in output (Vargo and Lusch 2004). In goods-dominant business logic, the product is the driver of new businesses for the firm, whereas SDL suggests that competitive advantages are created by the experiences the customer has over time and products are only the delivery vehicles for services (Vargo and Lusch 2008).

According to Miles (2005) knowledge-intensive business services (KIBS) have formed one of the most actively studied areas in services during the last twenty years. The foundation for segmenting KIBS as a sector of the economy is originally based on three-sector theory (Fisher 1935). Drucker (1966) extends the definition of KIBS; he describes knowledge economy as relying more on intellectual capabilities and knowledge-based professional services, rather than on physical activities or natural resources. Integrated and customized offerings are the baseline in the solution business. Solutions are cross-functional by their nature, as solutions can be seen as bundles of goods, services, and intellectual properties (Cova and Salle 2008). Storbacka and Pennanen (2014) define service solutions as processes that comprise identified value creation opportunities. The solution business requires simultaneous commercialization and industrialization, exploring the connection between the differentiation and divergence of the offering. Järvi (2016) emphasizes the complex nature of KIBS. Therefore KIBS offerings have traditionally been highly customized, strongly based on the specific context and needs of the specific customer.

Studies focusing directly on productization in KIBS are relatively low in numbers (Järvi 2016), but there are also studies that are linked to productization via parallel concepts. The commercialization of KIBS is a conversion of the offering where the focus is on a company's ability to understand the value creation process of its customers and is able to offer a solution that improves the customers' value creation processes. In KIBS sales, a company may also be able to change its pricing model based on transactions or provided value. Servitization is one of the major trends in service commercialization, referring to the process of creating value and gaining competitiveness by adding intangibility to tangibility (Baines et al. 2009; Wise and Baumgartner 1999; Harkonen et al. 2017). Based on SDL, in the commercialization of the co-creative process, services are not just added to products, but a product can be embedded in services and embedded products are only seen as the vehicles for service delivery (Vargo and Lusch 2014).

Originally, industrialization referred to the company's ability to standardize a solution in order to increase productivity (Levitt 1972). The original mass production approach has not found its way into service marketing but industrialization-based product portfolio management can give guidance for repeatability and scalability functioning as prerequisites for systematization (Järvi 
2016; Tolonen et al. 2015). Service solution platforms combine commercialization and industrialization activities, consisting of the company's subsets of capabilities that may or may not be visible to the customer. Solutions sales require cross-functional collaboration between the supplier's and customer's organizations (Kuula et al. 2015) when aligning resources in order to lead to a solution for the focal problem (Bonney and Williams 2009).

Modularity can be seen as a foundation for solution business. Solution marketing typically bundles products and services together, usually without any practical value creation. Sawhney (2006) sees the value of solutions as: "the value of individual products and services that make up the solution, plus the value of marketing and operational integration provided by the solutions vendor plus the value of customization for the customer's specific needs and context." Cost efficiency means implementing the service processes and related tasks correctly and getting the correct outputs from the inputs without wasting resources.

Based on SDL, value is embedded in value co-creation processes (Vargo and Lusch 2008). Because of the unpredictability of this process, it is difficult to maintain operational efficiency in honest co-creation (Prahalad and Ramaswamy 2004). In other words, efficient co-creation requires the simultaneous application of pull-driven, unstructured commercialization and a structured service process, based on the developed solution platform. The combination of these two important business drivers is notably less studied, and in particular, studies on their practical applications seem to be totally missing.

Combining the above discussions, the focus of this paper is on the cost-efficient delivery mechanism of KIBS that links the existing service modules and competences of the supplier to the values of the customer. Our aim is to systemize KIBS deliveries in order to clarify the value creation and increase the cost efficiency, and thus the profitability, of an organization. The former can be condensed into the following research questions (Fig. 1):

RQ 1: What are the approaches to systematizing a service offering?

RQ 2: What are the practical challenges when systematizing a service offering?

RQ 3: How can resources be linked to the modular cost-efficient co-creation of KIBS?

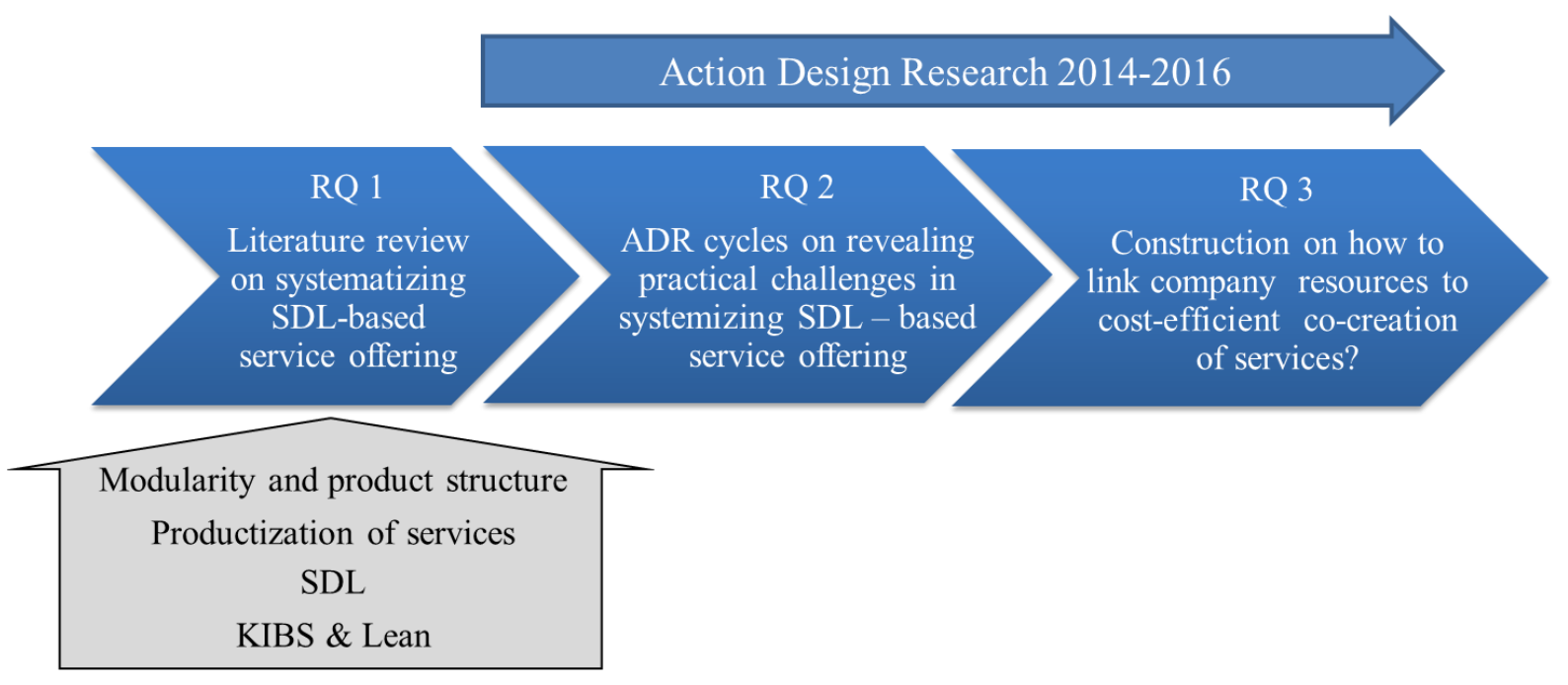

Fig. 1 The main logic of this study 
The cost-efficient productization and commercialization of co-creational KIBS lead to the need for systemization, raising the first research question, which we answer at the end of the literature review. Secondly, these approaches and their more accurate content have been analyzed in our case company while it has been pursuing systemizing service production in a value co-creational relationship. The practical challenges of service delivery systemization are explored through empirical action design research (ADR) addressed in RQ 2. We have closely followed and developed a KIBS provider over years, seeking cost-efficient and lean delivery processes while maintaining customer-centric value co-creation. The answer to RQ 3 comes at the end of this paper and is based on the presented theoretical framework and numerous ADR iterations.

\section{The theoretical framework}

In the relevant literature, discussions of KIBS have traditionally raised knowledge as a key resource of produced services. Leaning on uniqueness and the customer in the center typically lead to unique processes delivering the value, which is the opposite of lean thinking (Womack and Jones 2003). In turn, the value stream can be defined as competences, and co-creation generates pull for the customer-oriented value stream. Using KIBS and Lean as foundations (Fig. 2) we present a literature review for approaches on systematizing a service offering. Typically service is defined as a process that consists of a chain of activities (processes) (Davenport and Harris 2007). Services are created within interactive processes between the seller and buyer (Grönroos 2008), and solution marketing theories focus on marketing and managing the solution delivery (Sawhney 2006). SDL underlines the collaborative nature of value creation (Vargo and Lusch 2004; Payne et al. 2008). The delivery efficiency of services is studied through many different concepts, such as industrialization (Lewitt 1972), standardization (Tether et al. 2001), and systematization (Liden Björlin and Sanden 2004). In the past decade, these approaches have often been collected under the productization discussion (Jaakkola 2007; Järvi 2016; Tolonen et al. 2016).

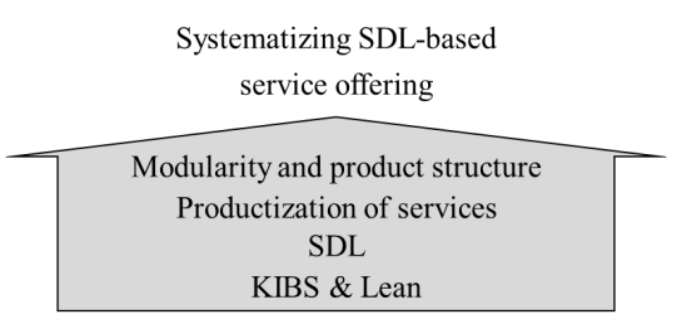

Fig. 2 The theoretical framework of the study

Further, productivity and organizational performance in service provision are viewed differently by different scholars (Järvi 2016). The immateriality and inseparability of the process and its outcomes mix the production-related components: efficiency and effectiveness. Efficiency is measured by process performance related to inputs and outputs. Effectiveness is measured by the achievement of set goals. These two components can be described as delivery efficiency and commercial effectiveness. Commercial effectiveness refers to value creation in the customer's eyes, where some degree of flexibility is required in each service encounter (Edvardsson et al. 2012; Brax 2005), and seeing value co-creation as the foundation of SDL is gaining ground. It is important to understand the difference between production and value creation: production is the process of making the resources available to customers who integrate those resources into the value creation processes (Grönroos and Ravald 2011). We have used modularization (Bask et al. 2010; Sawhney 2016), and further product structure (commercial [i.e., 
the customer view] product structure and technical [i.e., the supplier view] product structure), together with SDL (Vargo and Lusch 2004), to enable key approaches in the theoretical framework to separate the commercial offering from the service production, but also to connect them.

\subsection{KIBS}

The foundation for segmenting KIBS as a sector of the economy is based on three-sector theory (Fisher 1935). The three-sector theory divides economies based on their activity, producing materials (primary sector), manufacturing (secondary sector), and services (tertiary sector). Later Clark et al. (1967) supported Fischer's studies, underlining the fact that the main focus of the economy is shifting from the primary sector, through the secondary sector, to the third sector as the economy develops. As history shows, this has happened; in all the developed countries the tertiary sector has dominated the output of the economy for more than 20 years, accounting for over $75 \%$ of the economy in the most developed countries like the US, the UK, and France. Knowledge-intensive services are also introduced as the quaternary sector of the economy (Selstad 1990), although in the big picture, this sector can also be seen as a sub-segment of the tertiary sector.

The definition of KIBS has its roots in Drucker's (1966) The Effective Executive, which describes knowledge economy as relying on intellectual capabilities and knowledge-based professional services more than on physical activities or natural resources. The main content of KIBS offerings is knowledge (Järvi 2016). These knowledge-intensive (or also knowledgebased) services typically include information technology, media and culture, and research and development, as well as knowledge-based consultation, education, and design. KIBS firms provide knowledge-intensive support for the business processes of other organizations with a highly educated workforce, and their clients usually co-produce the service solution, along with the service provider, and both are aligned with SDL and value co-creation (Vargo and Lusch 2004).

A knowledge-intensive project organization (KIPO) is typically used in KIBS. These organizations often strive for co-creation close to the customer, which results in a need for distributing the employees and work to various locations, resulting in more customer-friendly solutions (Sydow et al. 2004). Our framework supports decentralized organizations in operationally efficient value creation by modularizing the technical portfolio.

Aarikka-Stenroos and Jaakkola (2011) demonstrated that, in the context of KIBS, customers may also exert a considerable influence on the formulation of the value proposition through negotiation and the contribution of their resources, and customers do not just actualize value by using what is offered to them (Gummesson 2008). Our framework is well aligned with this thinking; we suggest that customers influence the value proposition in a commercial portfolio and co-create value within the solution platform.

\subsection{SDL focuses on commercial effectiveness and created value}

The assumption that value is defined and co-created with the customer, where core competencies are the competitive advantages (Vargo and Lusch 2004), leads to a requirement for wide cross-organizational collaboration between the supplier and customer. Turning marketing logic, and thus business logic (Bolton et al. 2004), from "making, selling, and servicing" to "listening, customizing, and co-creating" requires alignment between marketing, development, and deliv- 
ery organizations, and the traditional value chain (Porter 1985) becomes pull directed. Slywotzky (1996) also presented a similar approach in his appreciated value migration theory, describing how a company selects its customers, and defines and differentiates its offerings based on the selected customer needs, defining the tasks it will perform and configuring its resources based on these.

Prahalad and Ramaswamy (2000) stated that value co-creation with the customer will replace the traditional goods exchange process. In a co-creational relationship, customers are part of the resource integration network, being simultaneously collaborators, co-developers, and competitors. A few years later, Vargo and Lusch (2004) introduced SDL, where service was seen as both a process (not an outcome) and as the application of competences that benefit each other (co-production). Later Vargo and Lusch (2008) replaced the term co-production with co-creation, but the relation between co-production and co-creation (Vargo and Lusch 2016) is the particular point of interest in this study.

Within SDL, service is the focus of economic exchange, which leads to a shift from operand resource exchange to operant resource exchange (e.g., competencies, knowledge, processes). Within this logic, the operant resources are the fundamental source of competitive advantage. Products are just a distribution mechanism for service provision (Vargo and Lusch 2004).

The eight original foundational premises of SDL (Vargo and Lusch 2004), were later translated into four core axioms (Vargo and Lusch 2014). These axioms focused on:

1. the application of resources in reciprocal service exchange (Vargo and Lusch 2004)

2. the integration of intangible and dynamic (i.e., operant) resources that create new resources (Vargo and Lusch 2004, 2008)

3. the co-creation of value through interaction and collaboration within networks of actors (Vargo and Lusch 2008)

4. the importance of the context through which value is created and evaluated uniquely by a beneficial actor (Chandler and Vargo 2011; Vargo et al. 2008).

Rather than focusing on different actors in global supply chains (e.g., a supplier of materials, a manufacturer, a retailer), SDL views all actors as resource integrators and co-creators of value (Vargo and Lusch 2014). In this view, all stakeholders are interconnected through the service provision, and value creation appears throughout the network at each encounter, not only at the end of the value chain, as it is in goods-dominant logic (Porter 1985).

SDL also claims that all actors (individuals, firms, nations) fundamentally do the same core activities in engaging with resource integration, exchanging service for service, and acting simultaneously as consumers and producers (Vargo and Lusch 2014). Edvardsson et al. (2012) further studied resource integration and value co-creation, suggesting that value is contextual and reliant on structure, which iteratively changes itself with every instance of resource integration.

Co-creation is neither the marginal customization of services nor it is the staging of customer events around a firm's various offerings, and therefore co-creation can be seen as an experience, not an offering. This experience is the basis of the unique value of each individual involved (Prahalad and Ramaswamy 2004). The benefits are clear: the firm learns more about its cus- 
tomers and can develop its offering accordingly, generating true partnership between the parties. Co-creative sales is a process embedded in value co-creation. Value creation is transparent, agile, and iterative.

The co-creational relationship also has some limitations. In-depth dialogue requires a lot of trust and agility from the customer, and the process is very time intensive. It is difficult to maintain operational efficiency in honest co-creation. Transparency requires an unusual degree of customer input into the solution delivery chain. Individual customers and consumers are at the heart of the co-creation experience, which makes it difficult to deal with the heterogeneous demands of the customer base. It is also difficult to define liabilities between the parties, and thus demand forecasting is difficult in this unpredictable co-creation environment (Prahalad and Ramaswamy 2004).

Commercialization refers to a provider's ability to understand the customer's value creating processes, create solutions that enable improved value creation for the customers, create demand for these solutions, sell the solutions to the individual customers, and receive compensation based on the customer's value-in-use (Payne et al. 2008). Therefore we can say that SDL focuses on commercialization more than production. Also Gronroos and Gummerus (2014) underline, that, according to SDL, the service providers cannot deliver value but can only make value propositions. In other words, efficient co-creation requires simultaneous pull-driven, unstructured commercialization and a structured service process, based on the developed solution platform. SDL and its core axioms can provide a solid framework for further exploration of the role of context in exchange, value proposition, and value creation in modern, digitalized, and globalized business and society.

\subsection{Productization covers commercial effectiveness and delivery effi- ciency}

SDL leads to the conclusion that suppliers' value propositions should be aligned with customers' strategic needs (which are dynamic and constantly changing), together with the resource integration structure, requiring transparent collaboration through suppliers' and customers' organizations. In other words, in co-creation the service is embedded in customers' value creation. This leads to the fact that the balance between efficiency and customer-orientation is a familiar challenge in all service companies (Kuula and Haapasalo 2016).

Digitalization is breaking barriers between industry segments and changing traditional value chains, which is driving even the most traditional industrial product businesses to add value through the provision of services (Baines et al. 2009; Howard and Caldwell 2011). This provision is commonly referred to as servitization (Vandermerwe and Rada 1988). Olive and Kallenberg (2003) illustrated the degree of servitization (another angle on productization) with the product-service continuum, where the offered product-service systems (PSS) are always seen as a combination of tangible and intangible elements. Definitions of PSS vary between studies: Tukker and Tischner (2006) refer to PSS as a value proposition, which is well aligned with our view of the commercial structure of servitization. Researchers across disciplines agree that PSS is not only changing business design and delivery mechanisms but that it is also changing the way in which customers consume, the value-in-use of goods, and the value co-creation of services, making operational delivery system management challenging (Neely 1999). Servitization and productization are related, approaching the same product-service continuum from different 
ends. Nowadays, these are both usually components of delivery, and commercialization defines which one dominates the marketing and business approach.

Delivery efficiency is currently discussed from many different perspectives. Originally some industrialization-related theories were applied (Lewitt 1972), then standardization (Tether et al. 2001) and systematization (Lidén and Sandén 2004). In the past decade, these approaches have often been collected under productization's definition (Järvi 2016). Grönroos (2008) described the product as something that can be developed, produced, delivered, marketed, and consumed, and originally productization was the systematization of service delivery (Järvi, 2016). Productization also has another discipline in making the offered services more tangible and concrete for commercialization purposes (Harkonen et al. 2015). In this study, our focus is on cost efficiency more than marketing, and therefore we are more interested in delivery-related organizational and operational service production, where the productization of services means standardizing the service processes so that they resemble products, making service delivery less complicated and more replicable (Jaakkola et al. 2009).

According to Jaakkola et al. (2009), the first step of productization is to define the service. A service's definition includes customer value; the service promise; and the core, supportive, and additional services for the service package. The second step in their model is to standardize the service. The sub-steps estimate what kind of standardization level fits the service and then divide the service into standard and tailored parts. Data collection principles, other standardization methods, and communication tools to support customer communications are defined. Then an important task is defining the customer's role in the service delivery and customer support for that role. Finally, the company must estimate if external help is needed in the standardization. The third step is to make the service concrete for the customer. This step is started by making sure that everyone in the company communicates the service in a similar way. Then the tangible elements that are used to communicate service contents and quality are defined. The concrete goods that will be added to the service are also designed. It is also important to make sure that the customer expectations of the service are set to the right level (Shostack 1984; Fitzsimmons and Fitzsimmons 2004).

\subsection{Modular (platform) product-service delivery is key for separating cost and profit structures}

Modularization refers to a process, product, or service structure where the elements of its design are split up and assigned to modules with well-defined interfaces according to a formal architecture or plan. Modularity makes engineering more flexible and makes outcomes more modifiable, and modular design makes a platform able to meet a larger market, generating efficiency in production and therefore more value-in-use. Customizing products by using a modular production platform is an established way of serving a heterogeneous market efficiently (Baldwin and Clark 2000).

Industrialization refers to the company's ability to effectively develop a solution, describing all the tasks that they aim to standardize, modularize, and productize in the solution, creating the basis for scalability and repeatability. The service production and service processes - called the solution platform - in conjunction with modularity, are prerequisites for repeatability and scalability. Solution platforms consist of the company's subsets of capabilities that are not visible to the customer. Platform thinking can be used to identify and use the modular structure and logic of activities, and customer offerings in service commercialization. Unlike product platforms, which have become standard tools in operations management, service platforms have received 
limited attention in practical business management and academic service research (Sawhney 2006).

As presented earlier, the service business can be developed by productizing the service offering to create the prerequisites for repeatability and scalability, defining and implementing the orderdelivery process for improved process performance (Järvi 2016). Modularity and platform thinking mean dividing the production process into modules, allowing a complicated process to be split up among different producers and using the same components to create different experiences for different target markets. In addition to production structure, modularity can also be found in the use of products, and therefore a wide range of services are also modularized (Sawhney 2006; Stenroos and Jakkola 2011). The service element is the equivalent to a product component. Thus, service elements are considered here as the smallest units into which services are divided (Fig. 3). Modularity can be seen in three different dimensions: modularity in services, modularity in processes, and modularity in the organization (Pekkarinen and Ulkuniemi, 2008; Baldwin and Clark 1997).

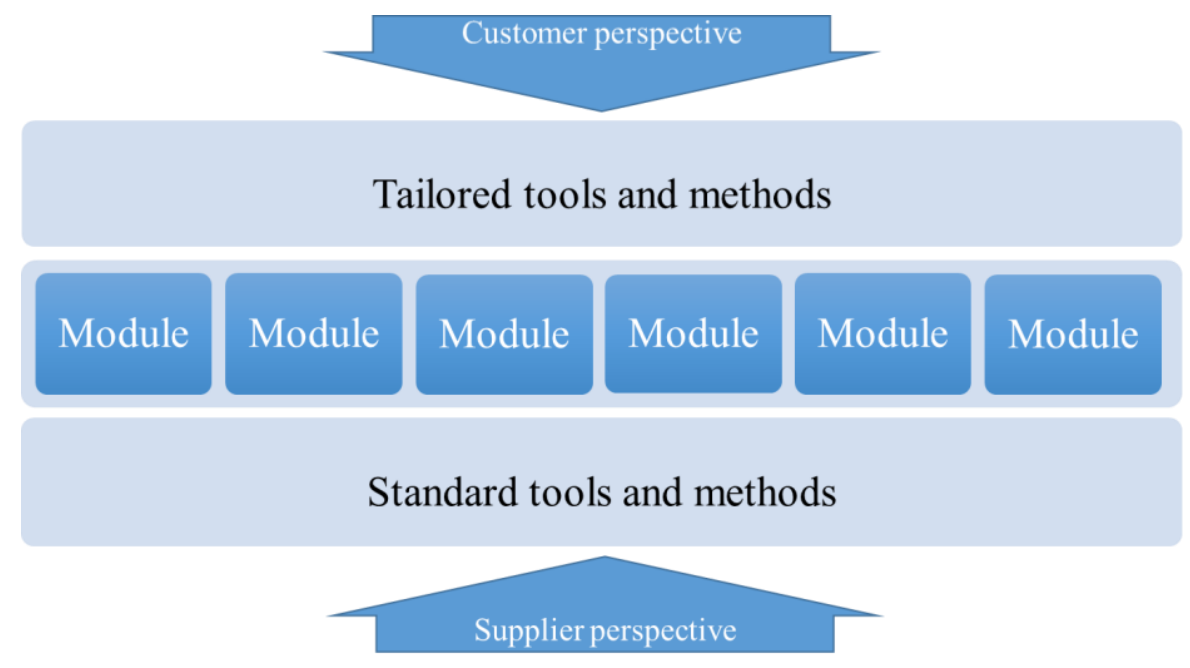

Fig. 3 The standardized, modularized, and tailored parts of a service (modified from Jaakkola et al. 2009)

Value co-creation literature commonly assumes that suppliers make a value proposition, and customers actualize value by using what is offered to them (Gummesson 2008; Vargo et al. 2008). Within this value creation architecture, productivity improvement through modularity can be achieved in the diagnosing process, design process, managing process, and implementation process. The modularity-driven standardization of repetitive tasks is important in increasing efficiency, while each of these service processes requires some degree of autonomy as each customer is unique and activities during the process are based on different conditions each time (Pekkarinen and Ulkuniemi 2008).

Defining services helps a company to fulfill the following service delivery capability requirements: repeatability, volume, quality, efficiency, load balancing, analytical development, customization, modularity, and communication (Saaksvuori and Immonen 2008). The product model of services includes service contents and a structural plan of the service products. Activities related to service structure planning and understanding the service contents can be called service (or product) portfolio management (Jaakkola et al. 2009).

Sawhney (2016) takes another view of modularization, seeing developing products to be embedded into services. Hence the focus is seen to be on internal processes. From the perspective of offering development, this is a conversion, not a creation, and this kind of productization can 
even be invisible to the customer. In this approach, the product is a repeatable task and is embedded as an element in a service. For the maximum gain, these products should be relatively unsophisticated and have a minimal need for tailoring (but they may have the ability to learn). The algorithms of automation are strong, especially in high-volume repetitive tasks.

\subsection{Product structure is replicable in services, focusing on delivery effi- ciency}

In SDL all the actors are seen as resource integrators, co-creating the value and thus solving the problems and defining the outcome together. Stenroos and Jakkola (2011) described collaborative problem solving in KIBS through their definition of value-in-use, where the supplier is advising, organizing, amplifying, and supporting value creation. A customer brings industry expertise, goals, the schedule, budget, financial resources, and his or her other available expertise to co-creation.

In the customer-oriented dynamic business environment, it is important that KIBS not only develop and provide the right operant resources (skills, competences, processes) at the right time but can also develop internal processes for competitive and cost-efficient service delivery. Internal process development covers the methods and tools for doing things right and the service management for doing the right things (Kuula et al. 2015).

Product management literature divides productization and product portfolio management into commercial and technical parts (Tolonen et al. 2014). A commercial product portfolio (Fig. 4) describes a company's offering for the customers and sales organization; this is also called commercialization. A technical product portfolio structures the technical solution for products as they are engineered, supplied, and produced inside the company and by its suppliers. The price of the product is defined by the commercial product portfolio and its cost by the technical portfolio (Tolonen et al. 2014).

A commercial product portfolio defines service products, service configurations, product families, and solutions. In the co-creational SDL environment this definition is pull driven, based on customers' individual needs and resources. If the service delivery has a clearly defined "bill of deliverables," the product management approach to the technical structure of the delivery can be taken. Hierarchically, HW and SW products are usually built from components and assemblies, whereas in a service product context solution platforms are used to enable service processes, component production, and the architecture for composing intangible deliverables together. 


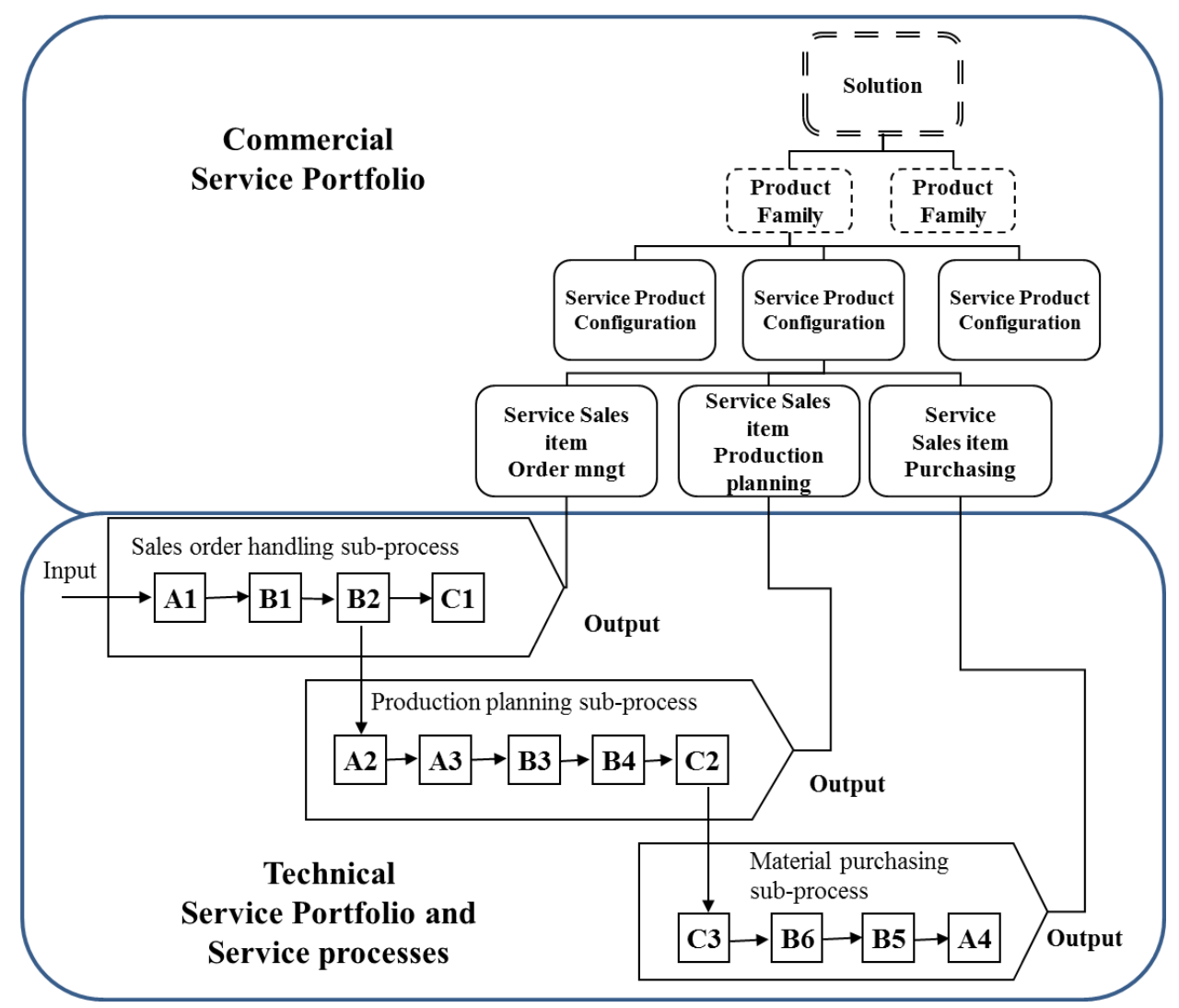

Fig. 4 Service productization, based on commercial and technical service portfolios (modified from Tolonen et al. 2015)

\subsection{Lean thinking focuses on customer-centric efficiency}

Lean thinking was first initiated in the Toyota Production System (TPS), then broadened as a leadership concept in the late nineties, and finally explained as a management philosophy at the beginning of this millennium (Liker 2004). The critical measure for lean thinking is value, which is determined and defined by the customer. All the work in the firm can be divided into value-adding activities or waste. In lean processes, the quality of service must be built into the system, and processes should be continuously improved, striving for perfection. The principles of lean thinking are 1) respect for people, 2) continuous improvement, 3) a pull-directed process, 4) solving root problems, 5) continuous learning in organization and partner networks, and 6) long-term thinking over short-term goals (Ohno 1988).

In the TPS, personnel represent core competences, and core competence in a service society is the basis of exchange. Good employee experience is the foundation for a good customer experience. Continuous improvement should be part of the company culture. This leads to the iterative approach to process development and organizational learning. In efficiency development, visual controls and transparency support cross-functional learning; titles are not important but respect for others, teamwork, and mutual trust are (Kuula et al. 2015).

Value stream mapping is key in lean thinking, having the following steps: 1) identify value (defined by the beneficiary, in the pull direction), 2) map the value stream (seamless resource integration with the customer), 3) create flow (cross-functionality, culture), 4) establish pull (co-creation with the customer), and 5) seek perfection (iterative development) (Womack and Jones 2003). Lean thinking sees value creation from the customers' perspective and learns, iterates, improves, and revisits the definition of value. When the provided value is defined, the 
firm has to define both the process and target costs for running the service, and all the waste from the process is removed (Womack and Jones 2003). In short, this means that the value of the service is co-created with the customer, the price for the value is defined by the customer, and the cost for running the service is defined by the supplier.

Ries (2011) presented a lean startup philosophy in order to answer the question: How can we learn what works more quickly and discard what does not? A learning process called buildmeasure-learn (BML) is clearly based on value creation and can be seen as the lean encountering process. The iterative BML process is the core part of the lean startup methodology, explaining how the ideas can be turned into products iteratively, measuring value creation from the customer's perspective, and then learning whether to persevere or pivot the idea. Haeckel's (1999) sense-and-respond centered view bridges lean startup philosophy and SDL's foundation. The main idea in the sense-and-respond approach is to cultivate relationships that involve customers in developing customized, competitively compelling value propositions to meet specific needs. Maurya's (2012) Running Lean describes the lean startup approach with a process for iterating the plan before running out of resources. It tackles the definition of co-creative value, where ideas and vision are tested with the minimal waste of resources.

\subsection{Synthesis of the theoretical framework}

KIBS sets knowledge as a fundamental resource for service business. SDL frames co-creation as a baseline for the value stream, aligning it with the pull-directed value stream of lean thinking. In both philosophies, the customer determines the value of the offering. KIBS and SDL also names operant resources (competences, i.e., knowledge and processes) as the key components of service delivery but leaves the door open for "packaged" services, called productization in this paper, although developed products are only seen as components in value delivery. In SDL commercialization does not start with the product; solution design begins with an analysis of a customer problem and ends with the identification of the products and services that will be needed to solve the entire problem (Vargo et al. 2004).

The main aim of this review is to outline the contribution of different discussions for systematizing service delivery (Table 1).

Table 1 The main content of the theoretical framework

\begin{tabular}{ll}
\hline The literature approach & The main content \\
\hline KIBS & Intangibility \\
SDL & Knowledge as the main resource \\
& Service as a process \\
& Co-creation and co-production \\
& Commercialization \\
Productization & Servitization \\
& Product service systems \\
& Industrialization, standardization, systematization \\
Modularity & Scalability, repeatability \\
& The service platform \\
Product (service) structure & Efficiency improvement of service elements (modules) \\
& The commercial (customer) part of service \\
& The solution platform \\
Lean & The technical (supplier) part of service \\
& Efficiency and effectiveness \\
& Customer value, value stream, flow, pull, continuous improvement \\
\hline
\end{tabular}


The core is customer liaison management, also called encountering, a key function in service development in KIBS. Payne et al. (2008) explored value co-creative encountering in the context of SDL and developed a conceptual framework for managing value co-creation between customer and supplier (Kuula et al. 2015). Just as competence development should be pull directed in the KIBS environment (Fig. 5), the developed components should be customer cocreated, proven solutions, repetitive, and unambiguously described (including their interfaces) (Pekkarinen and Ulkuniemi 2008).
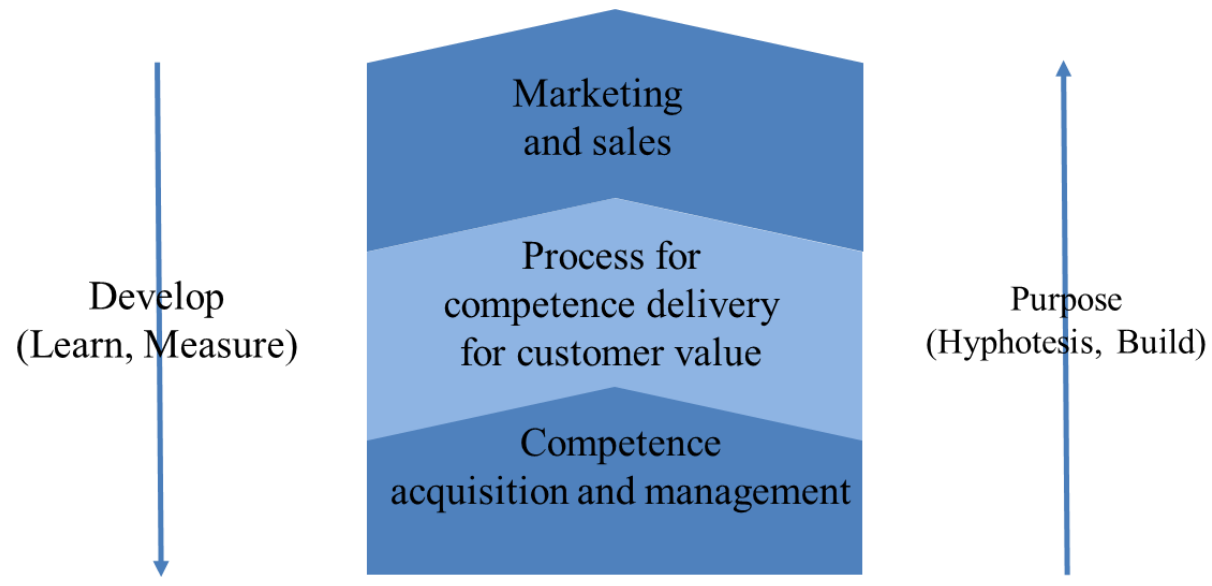

Fig. 5 The value-based competence development process, applicable for productized components (modified from Kuula and Niemi 2016)

Productization is a process for making services more tangible and/or repeatable (Järvi 2016). In contrast to SDL, productization is very much delivery oriented. A modular service portfolio approaches service delivery from the systematization perspective and is therefore related to productization. Unlike productization, modular service delivery aims more at cost efficiency than tangibility. Modularity is usually based on service platforms and/or "productized" components, which are delivered as a part of the value stream (Pekkarinen and Ulkuniemi 2008).

For bridging the literature research to practice, we composed content for the framework where KIBS deliverables are split into three categories: the technical portfolio, the commercial portfolio, and the solution platform (which integrates the two portfolio dimensions). Based on service marketing and SDL literature, the delivery items are competences and processes, andbased on SDL, modularization, and productization theories - products are the delivery mechanism for services. The technical portfolio consist of building blocks, along with the competences and capabilities from the delivery perspective. The commercial portfolio describes the sales items or values that the customer finally receives. The solution platform explains the cocreation done with the customer. In our literature review, we found delivery efficiency to be separately dependent of each different deliverable, seeing competence as a foundation, processes as being for systematization and reproducibility, and modular service components as being for the further improvement of delivery efficiency in KIBS (Fig. 6). 


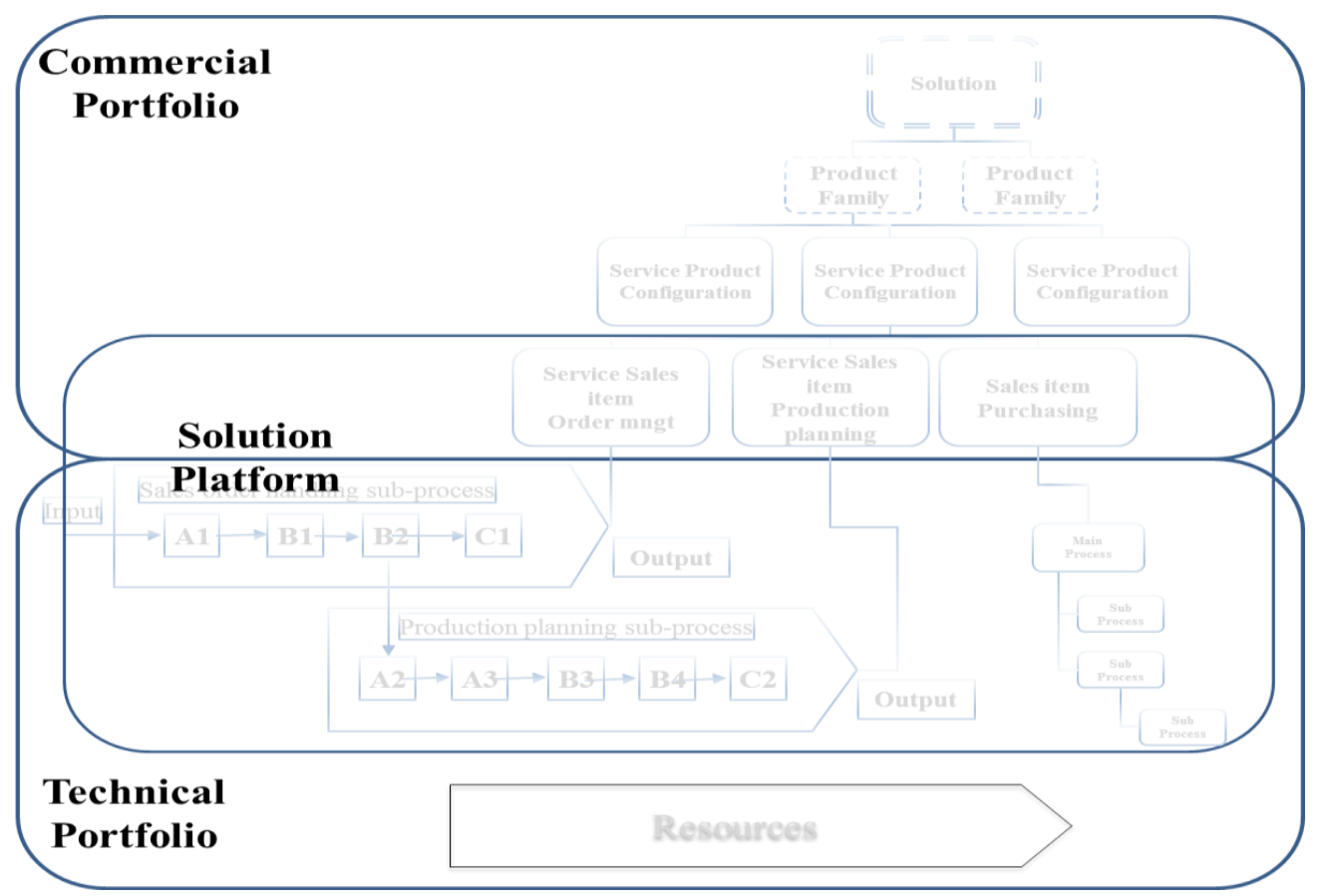

Fig. 6 The modularized service delivery process for systematizing a service offering

\section{Methodology}

The empirical part of this paper is a single case study, following the principles of ADR (Sein et al. 2011). This case study is iterative in its nature, aiming to improve the operational efficiency of service deliveries. ADR is practice-inspired research, resulting in a theory-ingrained artifact. In line with ADR methodology, our ADR cycles consists of four stages: 1) problem formulation, 2) building, intervention, and evaluation (BIE), 3) reflection and learning, and 4) formalization of the learning (Sein et al. 2011).

The first author has had a central development role in the case organization and acted as an "involved researcher" and the other authors act as the "outside researchers" in order to ensure the objectivity of the results (Walsham 1995; Walsham 2006). Besides the authors, several members of the case organization participated in the development and implementation of these cycles.

The research process had two main ADR cycles (Fig. 6) in order to find the solid state of the project delivery process, and it is entering the third iteration based on this study. The first ADR cycle was based on a current state analysis in 2014, seeking a formalized and measurable delivery process. An external researcher interviewed the management team and some key personnel during two months to describe the initial current state of the case organization, at which time the company identified competence management and project management as the key development areas defining lean project ownership (lean PO). The second ADR cycle started in 2016, mainly for creating better transparency all the way to the delivery, beginning from the delivery content commitments. After merging with another KIPO, more project-oriented business accelerated the importance of the topic and a focus on the development was sought through business measures. Naturally, there were also smaller iterations running inside these major ones. Finally, synthetization was initiated at the end of 2016, when the development of the 
commercial and technical structures of the project deliveries was focused on the same organizational entity and the sustainable maturity of deliveries. The main steps and key content are presented in Table 2.

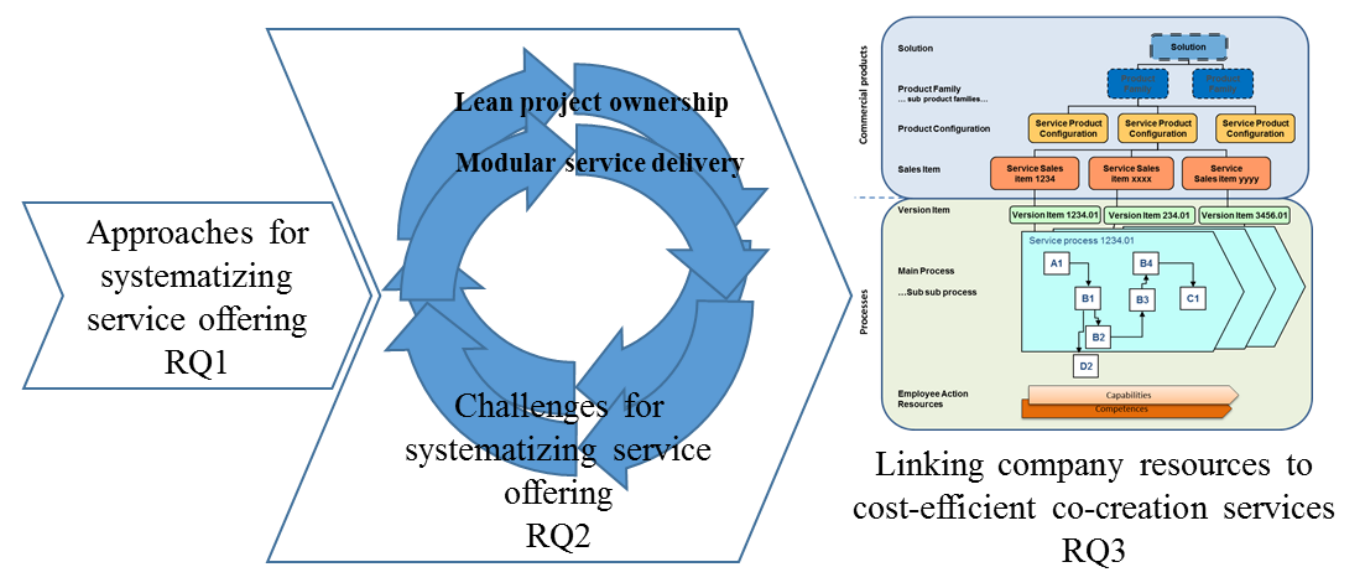

Fig. 6 ADR cycles in the case organization, and linking company resources to cost-efficient co-creation services

Table 2 The main steps of the ADR cycles

\begin{tabular}{|c|c|c|}
\hline & $\begin{array}{l}\text { Cycle } 1 \\
\text { Sustainable ground with lean PO (ADR } \\
\text { 1) }\end{array}$ & $\begin{array}{l}\text { Cycle } 2 \\
\text { Improving efficiency with mod- } \\
\text { ular service delivery (ADR 2) }\end{array}$ \\
\hline Problem formulation & Service delivery management & Components, productization \\
\hline $\begin{array}{l}\text { Building, intervention, and evalu- } \\
\text { ation }\end{array}$ & Lean PO & Component management \\
\hline Reflection and learning & $\begin{array}{l}\text { Sustainability supported in organiza- } \\
\text { tion }\end{array}$ & Process development, pricing \\
\hline The formalization of the learning & Processes & Solution definition \\
\hline
\end{tabular}

The final evaluation for the synthesis framework was made in confirmatory workshops at the end of 2016. In addition to these formal sessions, there have been numerous exploratory workshops with the project management office (PMO) of Siili Solutions PLC (hereafter Siili), customers and a service development organization. The basic processes for sustainable lean PO were recognized as being in use, and financial monitoring proved the development actions to be right.

When the baseline for the repeatable solution delivery was measurably proven; when organization, processes, and transparency were in place; and when the solution business met the same profitability level as process-oriented pricing, based on time and material, we finally got back to the original development target. This target was to optimize cost-efficient co-creation with the aim of improving Siili's profitability with systemized service component creation. This development is based on the earlier presented theory: modular productization as a part of service co-creation. 


\section{4. $\quad$ ADR Results}

\subsection{The case company}

Siili was founded in 2005 and provides data-driven design and technology-based KIBS to business-to-business customers. The sales revenue reached about $€ 50 \mathrm{M}$ in 2016 and it employs over 500 consultants in Finland, Germany, Poland, and the US. Siili has grown rapidly, while maintaining steady profitability. The average annual revenue growth has been over $40 \%$ with $10 \%$ EBITDA every year from 2010 to 2016.

Siili believes in a transparent, cross-organizational, and co-creational approach in its business model, seeking the position of a trusted digitalization advisor with its customers. Siili's value proposition is based on the SDL assumption that in a service economy neither product nor service creates value on its own and value is co-created with the customer, although value is always determined by the customer.

\subsection{ADR Cycle 1: Sustainable service delivery with lean PO}

The aim of the first cycle was to create efficient and repeatable processes for service delivery based on the presented theories and principles of lean thinking. The original problem formulation took place in spring 2014. Development and interventions were done at the beginning of 2015 and 2016, and in fall 2016. After every intervention an evaluation took place, and the following iterative action was based on this retrospectively. In 2016, we also went through the reflection and learning in the monthly management meetings between the second and the third intervention of this cycle. We formalized lessons learned in August 2016 and specified the second ADR cycle with modularized service components.

\section{The original problem formulation}

The initial state analysis of our delivery capability in 2014 revealed the fact that expertise acquisition, together with systematized competence management, met the requirements for growth, and the supporting organizational structure was sustainable but the company should invest in solution deliveries and related process development in order to be able to also deliver the frequently required transactional services (projects) more efficiently, in a repeatable manner, and with better quality. Transactional deliveries are especially required for new customer engagement in this case environment, especially in production-oriented industries. KIBS always have numerous variables in the offering, and immaterial digital service production is a complex environment to manage by its nature. The co-creational approach is agile and well scalable by its nature, but the delivery efficiency requires the capability of foreseeing the upcoming resource needs and identifying the potential use of standardized delivery components, processes, and practices. The challenge is in combining systematic competence management with efficient service delivery management without losing the agility and transparency of the co-creational encountering process.

\section{$B I E$}

As the first intervention, Siili's service development made a process development plan called Lean PO (Fig. 7) in order to respond to the above-described original need. The goal of Lean PO was to maximize the co-created value with minimal waste (inefficiency in the use of resources). 
In practice, this means maximizing customer satisfaction (value and transparency) and producer satisfaction (flow and resource efficiencies).

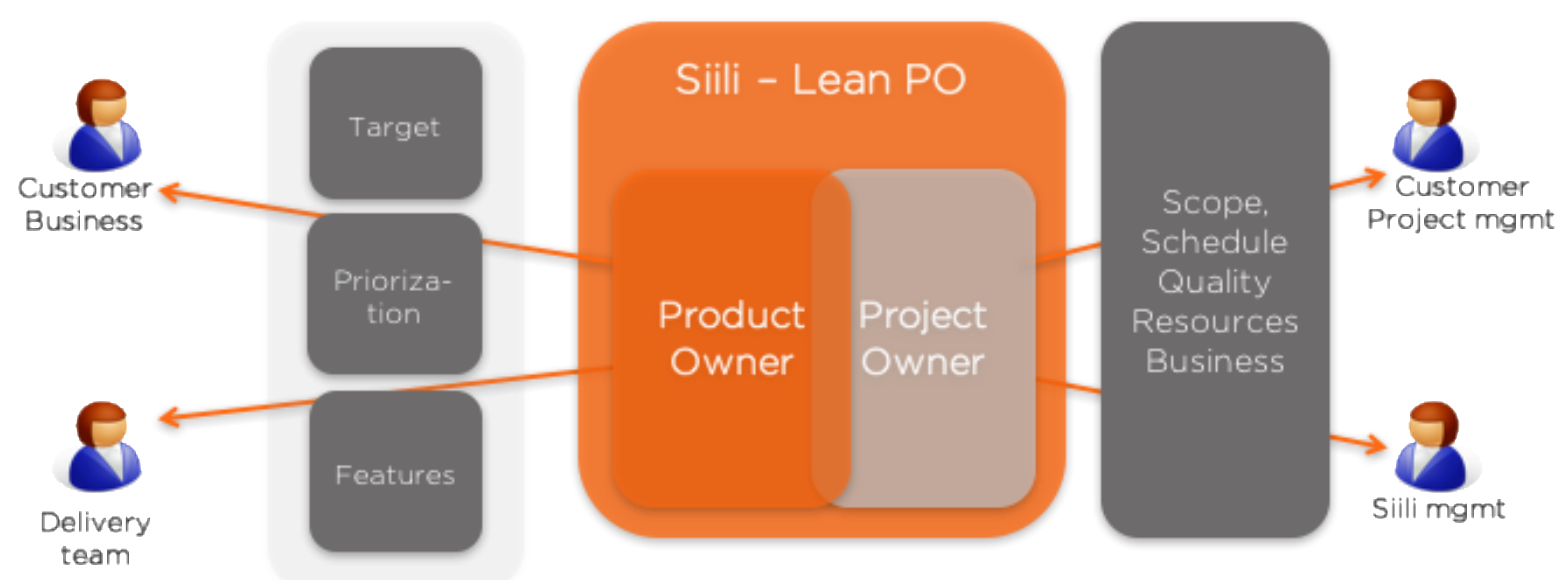

Fig. 7 Siili's Lean PO

This led to analysis of the value chain (from sales to project delivery and continuous services), providing the formalized descriptions of processes, identifying bottlenecks and waste, defining corrective actions, and identifying indicators with which to measure the effectiveness of the process and control it. Evaluation led to the following propositions: 1) to create a practical project in accordance with the principles of lean thinking, 2) to commercialize project delivery, 3 ) to create a knowledge base of best practices and work instructions, 4) to deliver process standardization.

After this intervention we learned that competence management and commercialization were developing further but that the repeatable delivery process was found difficult to achieve, mainly because of fragmented development activities. As the second intervention, in an attempt to ensure reproducibility, we separated the project business from that of the rest of the organization in January 2015. A mistake that was later recognized was that the responsibility for project management process development (among other processes) lay with the service development organization and, because of too many liaisons, the Lean PO methods were not well rooted in the delivery organization. At the end of 2015, in the middle of this ADR, the forecasted risks in the solution delivery process were realized as inefficiency in project deliveries was beginning to limit profitability, impairing the customer experience.

\section{Reflection and Learning}

Lean thinking requires determinate long-term commitment and iterative actions when striving for perfection, and as the practicalities of development in operations were never repeatable, we entered the new iteration. After the second intervention we revisited SDL and co-creational value creation (co-production) theories and encouraged service development and business management to submit development ideas for creating operational excellence for solution delivery. As the third intervention, the delivery development process was separated to become the PMO sub-organization inside the solutions business organization, which was evaluated in formal sessions, and its development was followed in the monthly management team sessions. We also established the process for the daily evaluation of transactional sales opportunities. The maturity of our project management was evaluated by each project (Fig. 8), and the plan for improving maturity was made and followed in monthly management meetings through the year 2016. 


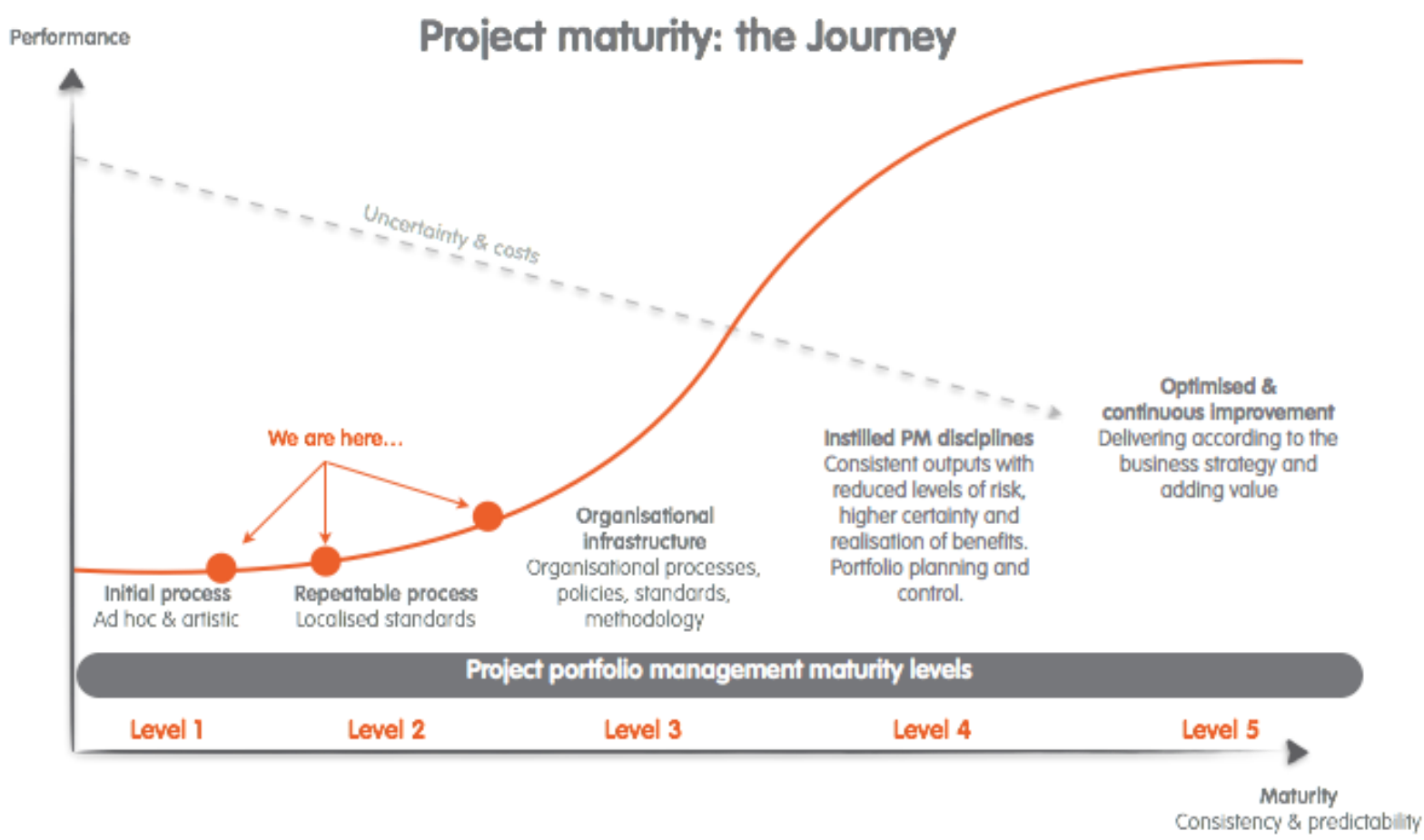

Fig. 8 The PMO's development path: the situation in spring 2016 (model adapted from the Project Management Institute)

\section{The formalization of learning}

Based on the workshops held June-August 2016, we found an immediate improvement in focus areas, and especially in the structural assessment, with daily project offering and planning meetings for workload balancing, and improved planning and estimation processes. This was a significant improvement, avoiding misleading definitions and scope, and preventing unproductive work.

During the ADR cycle, case company Siili achieved maturity in delivery processes, having an efficient competence management system in place, and repeatable processes and transparency for secure project deliveries. The original goal was achieved. The continuous growth and profitability of the company were sustained over the challenging development times. At the end of the ADR, the aim was to further improve profitability and separate KIBS-related revenue growth from its bond to profitability. This improvement was planned to be carried out by modularizing the delivery by using the productized service components in the project deliveries.

\subsection{ADR Cycle 2: Improving efficiency with modular service delivery}

Co-creation of the solution and resource integration are the foundational propositions of SDL and the cornerstones of Siili's delivery operations. Siili defines the solution together with the customer, based on the customer's individual needs, aligning and integrating the required resources and processes for solution delivery. In the earlier-described iterations we built a foundation for repeatable and efficient service delivery, and in this current ADR cycle (started in August 2016) our aim is to further improve delivery efficiency with predefined service components.

When a supplier is leading service production, the commercial model includes project management, and therefore processes are an essential part of the delivery. In this case, efficiency can 
be improved with the productized service components. These components are productized services, modules, which are developed to serve a certain need. These products can be sold separately, or preferably be used for making service delivery more efficient, depending the business model.

\section{Problem formulation}

In SDL, products are only seen as the delivery mechanisms for services, and that is also the aim in Siili's productization process. The customer does not need to see the productized service components in the value stream as the transactional value is based on the co-creational service definition. The aim in modularizing service deliveries is to save resources, reduce waste, and improve the quality of the deliveries with pre-tested components (Fig. 9).

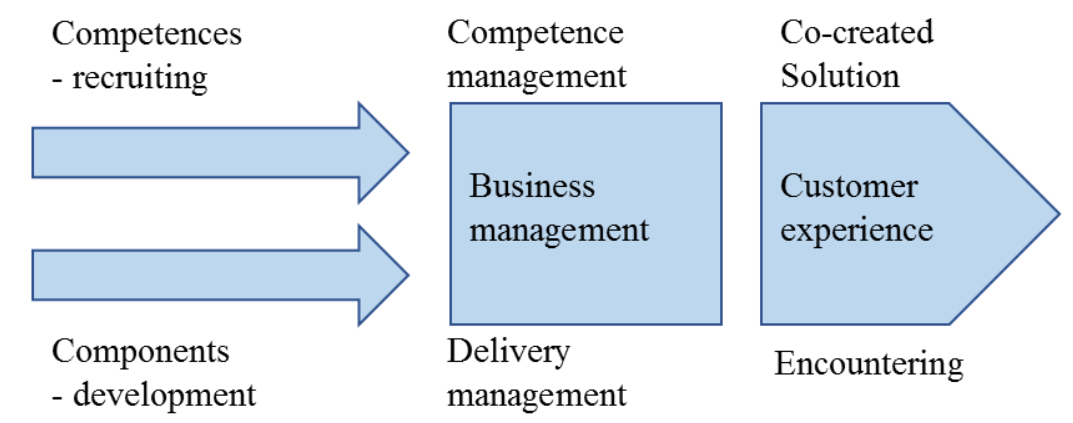

Fig. 9 The logic of modular service delivery management

\section{BIE}

Typical service delivery processes are always led by Siili's business management organization, for which a key performance indicator (KPI) is resource utilization, and therefore competence management is one of its key functions. Siili has been developing a competence management tool called KnoMe since 2012 in order to provide complete transparency on the stored competence data of all employees. Since then, the aim has been to develop a competence portfolio management system, including information on the ongoing and latest projects, and integration with the enterprise resource planning (ERP) system. At the beginning of this iteration KnoMe was serving the original purpose well, but the targeted components were also planned to be stored in the same system as the availability, usability, and interface information of the components; this seemed to be one of the greatest challenges of component usability. Siili's organization can be considered to have been flat from the beginning, and the solution definition empowered value-capturing consultants but the project delivery management process (Lean PO) is monitored by the separate PMO. Responsibility for component development and definition for KnoMe was given to Service Development organization as a strategic development project at the end of 2016, and the PMO was empowered to explore the possible component deliveries in project offering and planning meetings, called FUSE.

The modular delivery platform is built on the organization, where competences are developed and components are created based on the customer's existing and upcoming needs. Resource integration is done in the business units, where the technical structure of the deliveries is defined (Fig. 10). The commercial structure of the deliveries is co-created based on each customer's needs and the value proposition is based on the core competencies and repeatable processes. This may also be one of the next development cycles for the case company. In both of these models, delivery efficiency can be seamlessly improved with productized service components. The revenue model in co-creational work is mostly based on time- and material-based pricing, where these components are separately priced when used. 


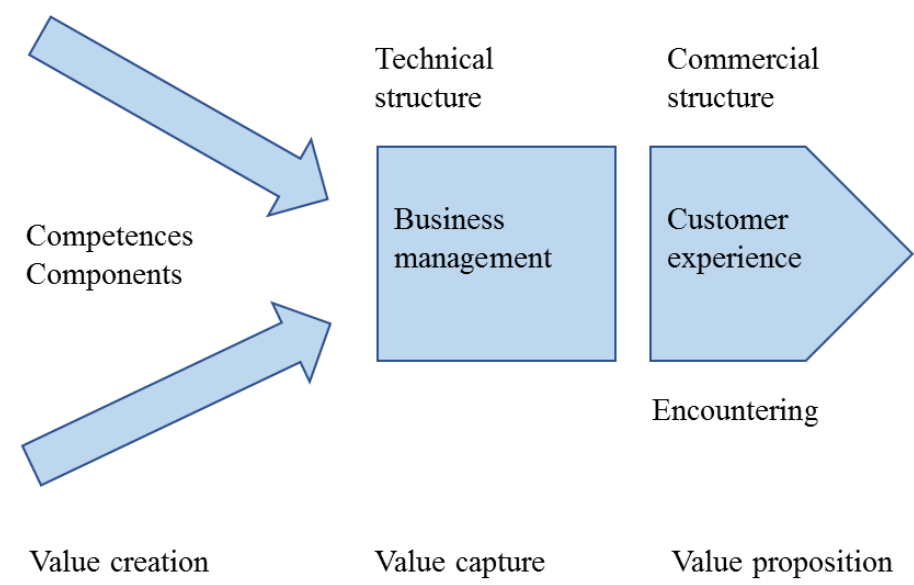

Fig. 10 The modular service delivery platform

\section{Reflection and Learning}

Based on the literature review, we defined the modularized service delivery platform, where we bridged the technical and commercial portfolio through identified processes related to delivery efficiency: competence management, encountering, and service management. This platform is used for understanding the required development path from resource integrator to the solution provider, finally focusing on sustainable delivery efficiency. The first components were used for deliveries during the first half of 2017, the coding environment setup in cloud storage and the access management module being examples. This intervention cycle ended in June 2017, although the development of components is continuing.

In the case organization, the technical portfolio has well-defined competence portfolio management and sustainable processes for systematized and repeatable service production. The case company uses the productized repeatable service components to further improve the cost efficiency of the service delivery. The delivery efficiency is defined to be related to 1) efficient competence management, 2) transparent encountering, enabling value co-creation, and 3) efficient service management, enabling re-use of the developed service components. At the time of writing this article it is too early to measure the reached value in service production, but the concept of modular service delivery platform is proven in practice.

\subsection{Practical challenges in service offering systematization}

Practical challenges from ADR 1 and ADR 2 can be compressed into Table 3.

Table 3 The main challenges in service offering systematization

Cycle $1 \quad$ Cycle 2

Sustainable ground with lean PO (ADR 1) Improving efficiency with modular service delivery (ADR 2)

1. Efficient (lean) project management

1. Definition of reusable delivery components

2. Agile delivery process management

2. Visibility to component mgmt

3. Combination of systematic competence manage-

3. Interface description of the defined components ment

4. Management of the solution delivery

with efficient service delivery management

5. Pricing the solution when the productized

4. The repeatability of delivery processes

components are used as a part of delivery

5. Project portfolio management 


\subsection{The cost-efficient co-creation of KIBS}

Siili's value proposition is provided by their commercial solution portfolio, consisting of both tangible service products and intangible services. In solutions, value is co-created with the customer and determined by the customer. Co-creation requires an agile, adaptable, and continuously improved encountering process and lean organization wherein people are authorized for value creation. Based on the service product management literature (Tolonen et al. 2015) and two major ADR cycles, we have created a framework for the solution platform as a cost-efficient co-creation of modular KIBS (Fig. 11).

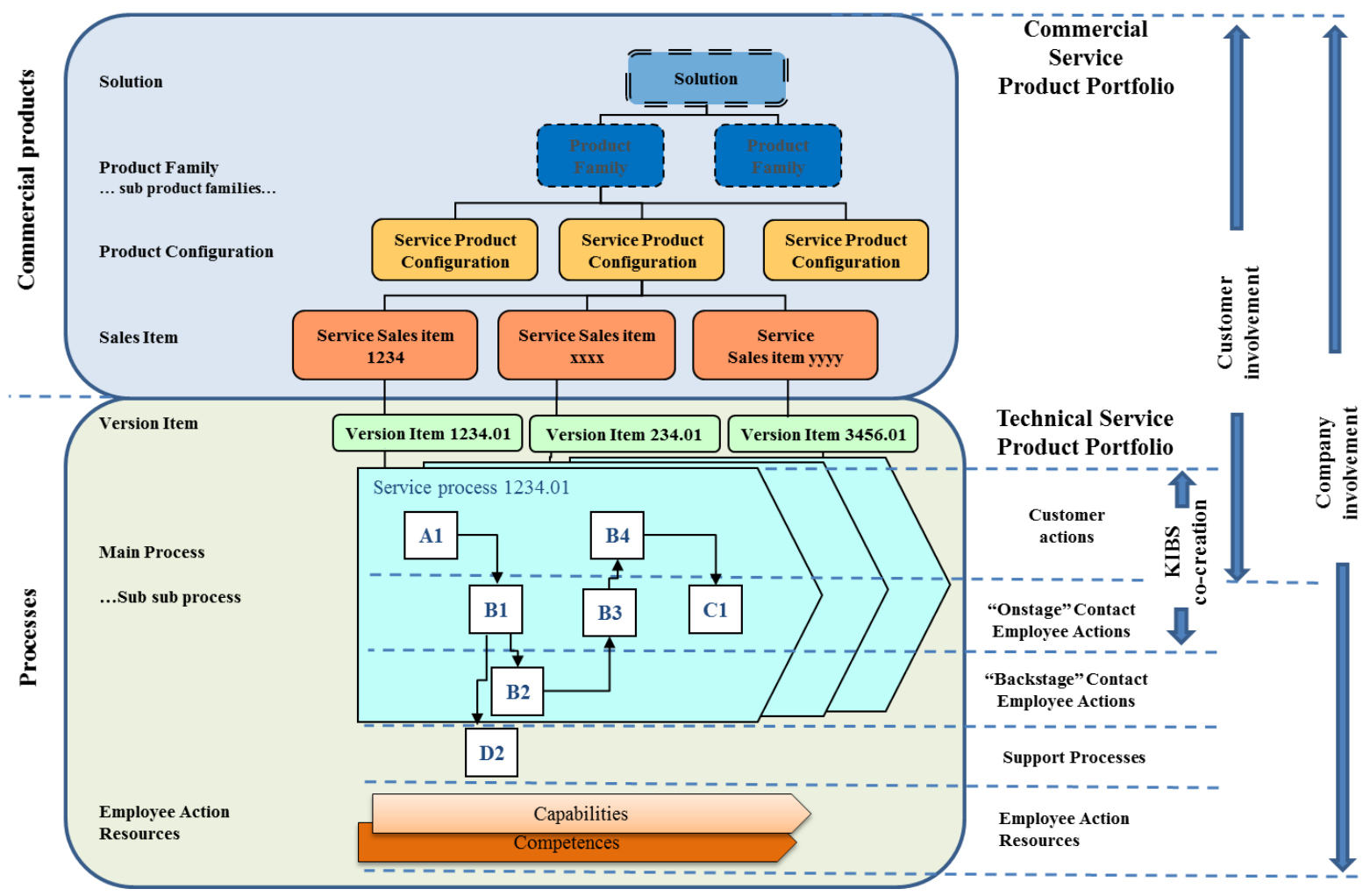

Fig. 11 Cost-efficient co-creation of KIBS

Based on lean thinking (Hines et al. 2004; Liker 2004; Womac and Jones 2003) Siili describes its internal processes as a value stream, where core competences are the value particles and suppliers' efficiency can be measured with value density (the level of competency, including supportive processes) and value stream density (the utilization rate of value-creating actions). Siili's service development organization is in charge of value density, whereas its business development organization is responsible for value stream density. Siili's customer experience organization is in charge of the commercial service product portfolio for value proposition, customer engagement, and customer experience. The customer encountering process is targeted to short iterations in the activity cycle, rapid prototyping cycles in service innovation, and using best practices in execution with full transparency and minimum waste of resources.

The solution platform for cost-efficient co-creation of KIBS includes commercial service product configurations, service sales items, and, on the technical portfolio side, version items and service processes. The commercial service sales items are connected to technical version items that consists of bill of service processes. Service processes involve both customer resources and the company's own resources. In practice the co-creational approach means that Siili's consultants, as "onstage employees," partly share the working premises with the customer. In addition, the company's "backstage" employees are involved in service processes. From a competence 
management perspective this way of working is challenging as 1) it is difficult to maintain an overview of the currently available competences of employees, 2) employees do not necessarily experience a strong enough connection with their employer processes and connect with the customer organization instead, and 3) Siili's competence portfolio created capabilities for service processes and sub-processes that are difficult to dynamically match with the numerous competence combinations of employees. The company has developed a strong competence management system and organization over the years (Kuula and Niemi 2016) but met these same challenges again with the development of the delivery component management process in this ADR.

Within SDL the technical service portfolio can be used for structuring processes to solutions in cost-efficient service production, but the pre-defined productization might be more challenging to achieve because customers are so evidently part of the delivery. In the SDL environment the co-creational service offering is aligned with the customer needs through the earlier-described encountering process. Value generation in this co-creational relationship is a process that includes actions from several actors: the service provider, the customer, and other parties. Encountering is an ongoing iterative collaboration between the marketing, business, and technology organizations of different actors.

\section{Discussion}

This paper is based on the view that, in service co-creation, the supplier's processes can be seen as a value stream, where competences and pre-developed products are the value components and suppliers' efficiency can be measured with value density (the level of competency), and value stream density (optimizing the utilization rate of value-creating actions). Professional service firms have a linear profitability growth challenge, whereas the same resources drive growth and costs. Modularization with the embedded products - putting products into services, also called productization - is proposed as a solution to this dilemma. This thinking is based on modularization theory (Sawhney 2016), productization theory (Järvi 2016), and SDL foundations (Vargo and Lusch 2004), which are bridged to lean thinking (Hines et al. 2004; Liker 2004; Womac and Jones 2003) and service management theories (Tolonen et al. 2015). The challenge is in productizing the professional service based on individual expertise, which requires the definition of a continuously co-creational solution.

The cross-organizational approach (business, technology, and marketing) for value co-creation requires lean organization, where people are respected and authorized for value creation, and full transparency for competences, components, and all stakeholders in the value chain. Personnel represent core competences, which in a service society are the base of exchange, but predeveloped components can improve the efficiency of value creation. Not all the modules need to be created from scratch as many of the problems and development phases are common for numerous customer projects, as seen in this ADR.

Based on our study we chose an approach where frequently performed service components were identified and productized. The challenge was not in structuring these components but in making them available and visible, not only to all project managers and product owners but also to all experts who may be able to use these components as a part of their deliverables. Cocreation is building trust, and creating commitment and a good customer experience. Co-creation confirms that the supplier is doing the right things. Productivity in the professional service 
business lies in the function between the unit price, capacity utilization, and internal efficiency. The customer determines the value of the outcome, so waste reduction can count towards the supplier's profit.

Service management is a key function in enabling the systematized delivery process, enabling the use of productized service components. As we learned in the study, this systematization is a demanding process when solution development is pull directed. Anyhow, we learned it is possible to reach and maintain a solid state with the structured technical portfolio. We also learned that the component definitions should be clear and easily available; in the case company we integrated component management into an advanced competence management system.

Modularity has already become a part of operations in many industries, aiming to gain more flexibility to meet the changing needs of customers. Productization is widely used for efficiently commercializing services, and service management theories are bridging these. Lean thinking has become a synonym for efficient production, and SDL is giving a new meaning to integrated value streams. This is a single case study in the KIBS business environment where we combine these frameworks together, and we cannot say that this approach can be used for any service delivery in any business environment. However, we do believe, that the managers of service organizations should pay attention to all of these dimensions (modularity, productization, commercialization, and service management) in maintaining efficient service creation while responding to customer needs in a constantly changing business environment.

\section{Conclusion}

Combining different discussions from the literature we can create a good foundation for a costeffective service offering (doing things right) and co-creational solution development (doing the right things). SDL defines operant resources as the base of value co-creation. In professional services, these operant resources can be split into competences, processes, and tools. The tools in this context are productized components, seen as modules in the delivery process. From the customer's perspective, the commercial commodities in KIBS are resources or transactions. In between these two different delivery models is co-creative value capturing.

We conducted this ADR in a professional service environment between 2014 and 2016. The findings extended our understanding of the productization of services, SDL and its encountering, competence, project and service management, and, finally, of process development. The commercial service product portfolio describes the service offerings as solutions, product families, service product configurations, and service sales items. The technical portfolio consists of version items, service processes, capabilities, and resources. The cost-efficient co-creation of KIBS links the customer's and company's resources to provide commercial sales items, service product configurations, and higher offering categories as product families, and customer and market segments. The technical portfolio describes the actual co-creation, based on the service processes. Lean thinking is the underlying key theory in systematizing the processes and value creation.

This study is a qualitative case study by nature. The main aim has been improving the efficiency of the commercial and technical service productization, offering, and delivery in the single case organization, thus analysis and external validity are somewhat limited. However, we believe that the results of this study could help numerous organizations in understanding the value co- 
creation in a KIBS scheme and in the optimization of efficient service production, based on a well-described service processes. For this reason, the final model is presented on a generic level in this paper.

Sein et al. (2011) defined that ADR should result in a theory-ingrained artifact that is intended to solve a practical business problem. The theoretical contribution in this study is focused on structuring the co-creational service delivery framework, exploring the commercial encountering following SDL, and modularizing the technical service delivery process in order to reach sustainable cost efficiency. In this framework, we bridge the technical and commercial portfolios through the identified delivery efficiency related processes: competence management, encountering, and service management.

The customer may or may not be aware of the modularized service process, but gains the benefit of productized commercial services. The company should either have a transactional or valuebased pricing mechanism for commercial service sales items and service configurations. The cost part of the services can be defined based on the cost of service processes that consist of tasks, resources, and even tangible material. Our aim is to explore value-based pricing in an upcoming study. In that study we will reveal the results of modularized service production after the required experience is gained and data collected.

The managerial implications of this study involve the cost-efficient co-creation of KIBS, based on the commercial service product portfolio and technical service process portfolio according to the product structure concept. The commercial service products, as service product configurations and service sales items, can be priced based on the customer's value of the service or based on the cost of service processes. By knowing the cost of services for a technical version of the item, the minimum price for the connected service sales item can be defined. The cocreation of KIBS involves both customer and company resources. The consultants of the company can be seen as onstage employees, working with the customer resources that are supported by the company's backstage employees. The profiles and skills of the onstage and backstage employees may differ, thus the competence and capabilities of them vary as well.

Finally, this research provides new evidence of how SDL can be applied in an authentic professional services context and the help of KIBS in developing a competitive offering with repeatable service production. The model described in this paper fulfills the criteria of a "weak market test," meaning that the management of a single company has applied this construction and appreciates its usefulness. We encourage other researchers and practitioners to apply the same frameworks and constructions in other companies in order gain more scientific evidence.

\section{References}

Aarikka-Stenroos L, Jaakkola E (2012) Value co-creation in knowledge intensive business services: A dyadic perspective on the joint problem solving process. Industrial Marketing Management 41 (1):15-26. doi: 10.1016/j.indmarman.2011.11.008

Baines TS, Lightfoot HW, Benedettini O, Kay JM (2009) The servitization of manufacturing: A review of literature and reflection on future challenges. Journal of manufacturing technology management 20(5):547-567. doi: 10.1108/17410380910960984

Baldwin CY, Clark KB (1997) Managing in an age of modularity. Harvard business review 75(5):8493

Baldwin CY, Clark KB (2000) Design rules. Volume 1, The Power of modularity, MIT Press, Cambridge MA 
Bask AH, Tinnilä M, Rajahonka M (2010) Matching service strategies, business models and modular business processes. Business process management journal 16(1):153-180, doi: $10.1108 / 14637151011017994$

Björlin Lidén, S, Sandén B (2004) The role of service guarantees in service development. The service industries journal 24(4):1-20. doi: 10.1080/0264206042000275163

Bolton R (2004) Journal of Marketing Vol. 68 (January 2004), 18-27

Bonney FL, Williams BC (2009) From products to solutions: the role of salesperson opportunity recognition. European journal of marketing 43(7/8):1032-1052. doi: 10.1108/03090560910961506

Brax S (2005) A manufacturer becoming a service provider - challenges and a paradox. Managing service quality $15(2): 142-155$. doi: $10.1108 / 09604520510585334$

Castells M (2010) The rise of the network society. 2nd ed. Wiley-Blackwell

Chandler J Vargo S (2011) Contextualization and value-in-context: How value frames exchange. Marketing theory 11(1):35-49. doi: 10.1177/1470593110393713

Cova B, Salle R (2008) Marketing solutions in accordance with the S-D Logic: Co-creating value with customer network actors. Industrial marketing management 37(3):870-277. doi:10.1016/j.indmarman.2007.07.005

Clark ME, Himwich WA, Martin JD (1967) Simulation studies of factors influencing the cerebral circulation. Acta Neurol. Scandinav. 43:189-204. doi:10.1111/j.1600-0404.1967.tb05728.x

Davenport T, Harris JG (2007) Competing on analytics: The new science of winning. Boston, Mass., Harvard Business School Press

Drucker, PF (1967) The effective executive: [the definitive guide to getting the right things done]. New York, Harper Business

Edvardsson B, Skålén P, Tronvoll B (2012) Service systems as a foundation for resource integration and value co-creation. In Special issue - Toward a better under-standing of the role of value in markets and marketing, Emerald Group Publishing Limited. 9:79-126. doi: 10.1108/S15486435(2012)0000009008

Fisher AGB (1939) Production, primary, secondary and tertiary. Economic record 15: 24-38. doi: 10.1111/j.1475-4932.1939.tb01015.x

Fitzsimmons JA, Fitzsimmons MJ (2004) Service management: operations, strategy and in-formation technology. 4th Edition, Boston, MA, McGraw-Hill/Irwin

Grönroos C (1979) An applied theory for marketing industrial services. Industrial marketing management 8 (1):45-50. doi: 10.1016/0019-8501(79)90017-8

Grönroos C (2008) Service logic revisited: Who creates value? And who co-creates? European business review 20(4):298-314. doi: 10.1108/09555340810886585

Grönroos C, Ravald A (2011) Service as business logic: Implications for value creation and marketing. Journal of service management 22(1): 5-22. doi: 10.1108/09564231111106893

Grönroos C, Gummerus J (2014) The service logic and its marketing implications: service logic vs service-dominant logic", Managing Service Quality, Vol 24 Iss 3 pp 206 - 229 doi:10.1108/MSQ03-2014-0042

Gummesson E (1999) Total relationship marketing: experimenting with a synthesis of research frontiers. Australasian marketing journal 7(1):72-85. doi: 10.1016/S1441-3582(99)70204-1

Gummesson E (2008) Extending the service-dominant logic: From customer centricity to balanced centricity. Journal of the Academy of Marketing Science 36(1):15-17. doi: 10.1007/s11747-0070065-x

Haeckel SH (1999) Adaptive enterprise: creating and leading sense-and-respond organizations. Boston, Harvard business school press

Harkonen J, Haapasalo H, Hanninen K (2015) Productisation: A Review and research agenda. International Journal of production economics 164:65-82. doi: 10.1016/j.ijpe.015.02.024

Härkönen J, Haapasalo H, Tolonen A (2017) Service productisation: systematising and defining offering Journal of Service Management 28(5):936-971. doi: 10.1108/JOSM-09-2016-0263

Hines P, Holweg M, Rich N (2004) Learning to evolve: a review of contemporary lean thinking. International journal of operations and production management 24(10):994-1011. doi: $10.1108 / 01443570410558049$

Howard MB, Caldwell ND (2011) Introduction. In Caldwell ND, Howard MB (Eds), Procuring Complex performance: Studies of innovation in product service management, Routledge, New York, NY 
Jaakkola E, Orava M, Varjonen V (2009) Palvelujen tuotteistamisesta kilpailuetua. Opas yrityksille. Helsinki: Tekes, 5

Jaakkola H (2007) Software architectures and the architecture of long-distance knowledge sharing, analysis and delivery platform. Proceedings of the first international symposium on universal communication, June 14-15, 2007, Kyoto, Japan

Järvi K (2016) Productization of knowledge-intensive business services: a managerial perspective. Aalto University. Doctoral dissertations, 126

Kuula S, Haapasalo H (2016) Continuous and co-creative business model creation. In service business model innovation in the healthcare and hospital management. Eds. Pfannstiel MA, Rasche C, 2016:249-268

Kuula S, Niemi E, (2016) Systematic innovation and service offering development in a knowledgeintensive project organization. Proceedings of the RESER 2016, European association research on services, New perspectives for business and society, September 8th-10th, 2016, Naples, Italy

Kuula S, Niemi E, Haapasalo H (2015) Service Dominant Logic - how to systematize service business. Proceedings of the RESER 2015, European Association Research on Services, Innovative services in the 21st century Copenhagen, 10. - 12. of September 2015

Levitt T (1972) Production-line approach to service, Harvard Business Review, (50)5:20- 31

Liden SB, Sanden B (2004) The role of service guarantees in service development. The Service Industries Journal 24(4):1-20. doi: 10.1080/0264206042000275163

Liker JK (2004) The Toyota Way: 14 Management principles from the world's greatest manufacturer. New York, McGraw-Hill

Maglio PP, Spohrer J (2008) Fundamentals of service Science. Journal of the academy of marketing science 36(1):18-20. doi:10.1007/s11747-007-0058-9

Maurya A (2012) Running lean: Iterate from plan a to a plan that works. Sebastopol, CA, O'Reilly

Miles I (2005) Knowledge intensive business services: Prospects and policies. Foresight. 7(6): 39-63. doi: $10.1108 / 14636680510630939$

Neely A (1999) The performance measurement revolution: Why now and what next? International journal of operations and production management 19(2):205-228. doi:10.1108/01443579910247437

Ohno T (1988) Toyota production system: Beyond large-scale production. Cambridge, Mass: Productivity Press

Oliva R, Kallenberg R (2003) Managing the transition from products to services. International journal of service industry management 14(2):160-72. doi: 10.1108/09564230310474138

Payne AF, Storbacka K, Frow P (2008) Managing the Co-creation of value. Journal of the academy of marketing science 36(1):83-96. doi: 10.1007/s11747-007-0070-0

Pekkarinen S, Ulkuniemi P (2008) Modularity in developing business services by platform approach. International journal of logistics management 19(1):84-103. doi:10.1108/09574090810872613

Porter ME (1985) Competitive advantage: Creating and sustaining superior performance. New York, London, Free Press, Collier Macmillan

Prahalad CK, Coimbatore K, Ramaswamy V (2000) Co-Opting Customer Competence. Harvard business review 78 (1):79-90

Prahalad, C. K., \& Ramaswamy, V. (2004). The future of competition: co-creating unique value with customers. Boston: Harvard Business School Press.

Ries, E (2011) The lean startup: How today's entrepreneurs use continuous innovation to create radically successful businesses. New York, Crown Business

Saaksvuori A, Immonen A (2008) Product lifecycle management. 3rd Edition, Berlin Heidelberg, Springer-Verlag

Sawhney, M (2006) Going beyond the product. The Service-Dominant logic of marketing: Dialogue, debate, and directions, 365-80

Sawhney M (2016) Putting products into services. Harvard business review 94(7):82-89

Sein MK, Henfridsson O, Purao S, Rossi M, and Lindgren R (2011) Action design research. MIS Quarterly 35(1):37-56

Selstad T (1990) The rise of the quaternary sector. The regional dimension of knowledge-based services in Norway, 1970-1985. Norwegian Journal of Geography 44(1):21-37. doi:10.1080/00291959008552242

Shostack GL (1984) Designing services that deliver. Harvard business review 62(1):133-139 
Slywotzky AJ (1996) Value migration: How to think several moves ahead of the competition. Boston, Mass, Harvard business school press

Starbuck WH (1992) Learning by knowledge-intensive firms. Journal of management studies 29(6):713740. doi: 10.1111/j.1467-6486.1992.tb00686.x

Stenroos L, Jaakkola E (2011) Value co-creation in knowledge intensive business services: A dyadic perspective on the joint problem solving process. Industrial marketing management 41(1):15-26. doi: 10.1016/j.indmarman.2011.11.008

Storbacka K, Pennanen R (2014) Solution business: Management for professionals. Cham, Springer international publishing

Sydow J, Lindkvist L, DeFillippi R (2004) Project-based organizations, embeddedness and repositories of knowledge. Organization Studies. 25(9):1475-1489. doi: 10.1177/0170840604048162

Tether BS, Hipp C, Miles I (2001) Standardisation and particularisation in services: Evidence from Germany. Research Policy 30(7):1115-1138. doi: 10.1016/S0048-7333(00)00133-5

Tolonen A, Harkonen J, Haapasalo H (2014) Product portfolio management - Governance for commercial and technical portfolios over life cycle. Technology and investment 5(4):173-83. doi:10.4236/ti.2014.54016

Tolonen A, Harkonen J, Verkasalo M, Haapasalo H (2015) Product portfolio management process over horizontal and vertical portfolios. International journal of product lifecycle management 8(3):189-215. doi:10.1504/IJPLM.2015.074132

Tolonen A, Verrollot J, Harkonen J, Haapasalo H (2016) Delivery capability management - integration of supply chain management activities on new product development. The 19th International working seminar on production economics 22-26th Feb 2016, Innsbruck

Tukker A, Tischner U (2006) Product-Services as a research field: Past, Pre-sent and Future. Reflections from a decade of research. Journal of cleaner production 14(17):1552-1556. doi:10.1016/j.jclepro.2006.01.022

Vandermerwe S, Rada J (1988) Servitization of business: adding value by adding services. European management journal 6(4):314-24

Vargo SL, Lusch RF (2016) Institutions and axioms: an extension and up-date of service-dominant logic. Journal of the academy of marketing science 44(1):5-23. doi: 10.1007/s11747-015-0456-3

Vargo SL, Lusch RF (2004) Evolving to a new dominant logic for marketing. Journal of marketing 68(1):1-17. doi: 10.1509/jmkg.68.1.1.24036

Vargo SL, Lusch RF (2008) Service-Dominant logic: Continuing the evolution. Journal of the academy of marketing science 36(1):1-10. doi: 10.1007/s11747-007-0069-6

Vargo SL, Lusch RF (2014) Inversions of service-dominant logic. Marketing theory 14(3):239-248. doi: $10.1177 / 1470593114534339$

Vargo SL, Maglio PP, Akaka MA (2008) On value and value co-creation: a service systems and service logic perspective. European management journal 26(3):145-152. doi: 10.1016/j.emj.2008.04.003

Walsham G (1995) Interpretive case studies in IS research: nature and method. European journal of information systems 4(2):74-81. doi:10.1057/ejis.1995.9

Walsham G (2006) Doing interpretive research. European journal of information systems 15(3):320330. doi:10.1057/palgrave.ejis.3000589

Wise R, Baumgartner P (1999) Go downstream: The new profit imperative in manufacturing. Harvard business review. 77(9):89-96

Womack JP, Jones DT (2003) Lean thinking: Banish waste and create wealth in your corporation. New York, NY, Simon \& Schuster 